\title{
Exposing concerns about vaccination in low- and middle-income countries: a systematic review
}

\author{
Daniel Cobos Muñoz • Laura Monzón Llamas • Xavier Bosch-Capblanch
}

Received: 11 March 2015/Revised: 2 July 2015/Accepted: 3 July 2015/Published online: 23 August 2015

(C) Swiss School of Public Health 2015

\begin{abstract}
Objectives Concerns about vaccination lead to under- and no-vaccination. Our objective is to synthesise and expose evidence on individuals' and communities' concerns about vaccination to influence current debates on strategies to improve vaccination coverage in low- and middle-income countries.

Methods Systematic literature review till February 2014, following standard methods. Published and grey literature that focused on individuals and community concerns on childhood vaccinations were selected.

Results 44 quantitative, qualitative and mixed-methods studies were included. Main reported concerns referred to perceptions of vaccine harms (e.g. attribution of fatal events). Other concerns included programme distrust (mainly due to rumours and conspiracies) and health system unfriendliness.

Conclusions Concerns about vaccination are widespread and further worsen the challenges related to programmatic and health system barriers to vaccination. There is a
\end{abstract}

This review is part of the special issue "Driving the Best Science to Meet Global Health Challenges" edited on the occasion of the 9th European Congress on Tropical Medicine and International Health 2015.

Electronic supplementary material The online version of this article (doi:10.1007/s00038-015-0715-6) contains supplementary material, which is available to authorised users.

D. Cobos Muñoz $\cdot$ L. Monzón Llamas · X. Bosch-Capblanch Swiss Tropical and Public Health Institute, Socinstrasse 57, 4002 Basel, Switzerland

D. Cobos Muñoz · L. Monzón Llamas · X. Bosch-Capblanch ( $\square)$ Universität Basel, Petersplatz 1, 4003 Basel, Switzerland

e-mail: x.bosch@unibas.ch disconnection between qualitative and quantitative research which misses the opportunity to quantify what is reported in the former. Strikingly, there is a wealth of evidence on concerns but much lesser evidence on interventions to address them. We welcome World Health Organization initiative to tackle vaccine hesitancy and call for the synthesis of evidence and production of guidance on strategies to address concerns on vaccination.

Keywords Concerns - Hesitancy - Vaccination · Immunisation - Systematic review . Low- and middle-income countries

\section{Introduction}

Vaccination programmes have become more complex over the last years due to the availability and introduction of new vaccines (WHO 2014a), the incorporation of other interventions alongside vaccination programmes (Wallace et al. 2009) (e.g. vitamin A supplementation) and the setting up of ambitious global targets for disease control, such as polio eradication (WHO 2012a) and measles elimination (WHO 2012b). These facts pose new challenges in the delivery of vaccines, especially in resource-constrained settings. The complexity of logistics, costs and strategies for delivering existing, underused and new vaccines has increased exponentially (WHO 2014b) and disease control targets require even higher vaccine coverage rates. Accomplishing these goals requires efforts at community level and in each tier of health systems and globally. Under- and no-vaccination remains a problem in many countries (Bosch-Capblanch et al. 2012), a challenge not only for health systems, but also for communities and families. Vaccination coverage has been increasing in the 
last decades worldwide; however, Sub-Saharan Africa coverage rates remain constantly below other regions, and countries within it show large disparities in coverage (WHO 2014d).

Perceived concerns about vaccination have been associated with suboptimal compliance with vaccination schedules in children, low vaccination uptake or even vaccine refusal (Brown et al. 2010; Falagas and Zarkadoulia 2008). Lack of confidence in vaccination has become a problem in many different settings (SAGE Working Group on Vaccine Hesitancy 2013a), for a wide array of reasons. Addressing this issue requires engaging consumers, journalists, decision makers, health care professionals and researchers (Larson et al. 2011). Lack of confidence in vaccines and health systems has strongly contributed to decreases in vaccination coverage and increases in morbidity and mortality of vaccine-preventable diseases (Brown et al. 2010). The problem has been recognised by policy makers, international institutions and the scientific community, motivating efforts to understand why the public lacks confidence in vaccination and what factors cause delays or even refusal to vaccinate.

The term "vaccine hesitancy" has become widely used for demand-side barriers to vaccination. According to the World Health Organization (WHO) Strategic Advisory Group of Experts (SAGE), the term refers to "a behaviour [related to vaccination], influenced by a number of factors including issues of confidence (do not trust vaccine or provider), complacency (do not perceive a need for a vaccine, do not value the vaccine), and convenience (access)" (SAGE Working Group on Vaccine Hesitancy 2013b). The SAGE is addressing the issue of vaccine hesitancy and guiding efforts to improve vaccination coverage (WHO 2013).

The objective of this review is to expose the perceived concerns on vaccination through a synthesis of qualitative and quantitative evidence on caregivers' concerns regarding vaccines included in the routine childhood vaccination schedule in low- and middle-income countries (LMIC).

\section{Methods}

We conducted a systematic literature review based on Cochrane methods (Higgins and Green 2011) and followed the PRISMA criteria for reporting of systematic reviews (Moher et al. 2009).

\section{Search strategy}

The following literature databases were searched (including grey literature databases): MEDLINE, Embase, Global Health, PsycINFO, CINAHL, Social Science Citation
Index, Campbell, WHO Global Health Library, Popline and Proquest Social Sciences Premium Collection (includes 14 social science databases). The search strategy is available as an Online Resource. The search was run for all databases until February 2014 for all years available. We structured the search strategy around four main concepts:

- Concerns: we adapted the search strategy developed by SAGE in their vaccine hesitancy systematic review (SAGE Working Group on Vaccine Hesitancy 2013b).

- Participants: individuals and communities receiving vaccinations.

- Immunisation: vaccines included in the childhood systematic immunisation schedule of LMIC. Searches were not limited by the way vaccines were delivered (e.g. routine immunisation, campaigns).

- LMIC: based on the World Bank List of Economies defined as "low income", "lower middle income" and "upper middle income" in 2014 (World Bank 2014).

\section{Selection of studies}

Any study design (i.e. qualitative, quantitative or mixedmethods) describing concerns about vaccinations in LMIC were included in the review.

Duplicate references were removed and studies were assessed for relevance using titles and abstracts. Relevant papers were identified and full texts were assessed for inclusion using a pre-specified set of criteria. Articles were included if: (1) the study context was a LMIC; (2) vaccines studied were included in childhood systematic vaccination; (3) the study population were individuals or communities (i.e. studies only focusing on health workers' concerns about vaccination were excluded); (4) the main focus of the study was on concerns about vaccinations; (5) the language of the full text of the document was in English, French, Spanish or Portuguese; (6) the study reported primary data; and (7) it was produced after the year 2000. All articles that met the inclusion criteria were included for quality assessment and data extraction.

Quality assessment

The quality of studies was assessed using criteria adapted from several quality assessment tools for qualitative (Bedford et al. 2013; Critical Appraisal Skills Programme (CASP) 2014) and quantitative studies (Effective Public Health Practice Project 2010; Jackson et al. 2005).

Quantitative studies were given an overall rating of 'strong', 'moderate' or 'weak' quality following the methodology described elsewhere (Effective Public Health Practice Project 2010). Qualitative studies were not given an overall rating or score as no consensus exists in this 
area. We rather present the results for each criterion in the quality assessment.

Methodological quality was not used to exclude studies or for subgroup analyses.

\section{Data extraction and analysis}

Qualitative and quantitative data were extracted using data extraction templates. Data were categorised according to a predefined set of themes and subthemes using those identified by Mills et al. in their review of parental beliefs and attitudes towards childhood vaccination (Mills et al. 2005b) (see Table 1 in the Online Resource).

Quotes referring to concerns about childhood vaccinations were extracted from qualitative studies. We extracted two main types of statements: quotes from respondents comments in interviews or participants remarks in focus group discussions (FGD), and authors' relevant statements in the discussion section of the articles.

Data extracted from quantitative studies included frequency measures of specific concerns and/or their impact on vaccination outcomes. Both point estimates and confidence intervals were extracted if available.

Results from quantitative and quantitative studies are reported in a narrative way following categories and subcategories. Vaccination status in most of the quantitative studies was self-reported.

\section{Results}

Description of the studies

The screening and selection process is represented in Fig. 1. 7012 hits were obtained, which yielded 44 included studies from 45 published articles. Tables 2, 3 and 4 in the Online Resource report the characteristics of the qualitative $(n=19)$, quantitative $(n=20)$ and mixed-methods $(n=5)$ included studies, respectively.

Included studies were conducted in 19 countries: 23 studies in Asia, 16 studies in Africa, four studies in South America and one in Oceania.

Qualitative data were available and extracted from 23 studies (17 qualitative studies, four mixed-methods studies and two surveys; two articles reported on the same study: Dasgupta et al. 2008 and Chaturvedi et al. 2009). The most frequent qualitative methodologies were FGD (14 studies) and in-depth interviews or key informant interviews (13 studies), followed by surveys with open-ended questions (four studies), ethnographic (two studies) and documentary approaches (one study).

Quantitative data were extracted from 25 studies (21 surveys, two case-control studies and two mixed-methods studies). 16 studies used structured interviews, one used self-administered questionnaires and eight used other types of data collection methods. These data represented a total of 14,981 participants (median 320, range 117 to 4442 per study). We found measures of frequency of specific concerns (usually expressed as a percentage of individuals who gave an answer to a question) and measures of association between concerns and vaccination behaviour or vaccination outcomes (expressed as odds ratios). We also found two main types of information. First, questions about knowledge or beliefs of interviewees about vaccination (e.g. percentage of people that believed that vaccination can harm); second, some surveys included questions regarding concerns as a reason for incomplete vaccination or non-vaccination. In cases where an indicator was estimated for a specific subgroup in the sample, we report the subgroup as defined in the original study.

Quality assessment

Tables 5 and 6 in the Online Resource show the detail of the quality assessment of the qualitative and quantitative studies, respectively.

We could not find any qualitative study that complied with all ten CASP quality criteria. Ten studies complied with eight or more criteria, 12 complied with five to seven criteria and one study complied with less than five criteria. All papers of qualitative studies properly reported the aims of the study and defined their methodological orientation. Ethical clearance, informed consent of participants and confidentiality were reported in six studies. Nine studies partially reported these criteria and seven studies did not report any information regarding ethics. The majority of authors reported their findings using quotes from the interviews or FGD to support their statements (17 studies). In most cases, non-compliance with quality criteria was due to incomplete or unclear reporting to assess the methods used. Finally, almost none of the papers properly explained the relationship between researchers and participants and only two papers fully explained the selection of participants.

The overall rating score for the methodological quality in quantitative studies was moderate for three studies and weak for the rest. None of the studies scored as 'strong' in the overall rating. Most studies $(n=22)$ were cross-sectional and three were case-control studies. In most of the studies, neither participants nor assessors of outcomes were blinded nor confounders were properly dealt with. Data collection was rated as 'strong' in eight studies and 'weak' in the rest. Only one case-control study reported loss to follow-up and the number of participants who completed the study. Only one of the estimates of frequency extracted was reported with confidence intervals. 
Fig. 1 Study flow diagram of the systematic review on concerns about vaccination in low- and middle-income countries

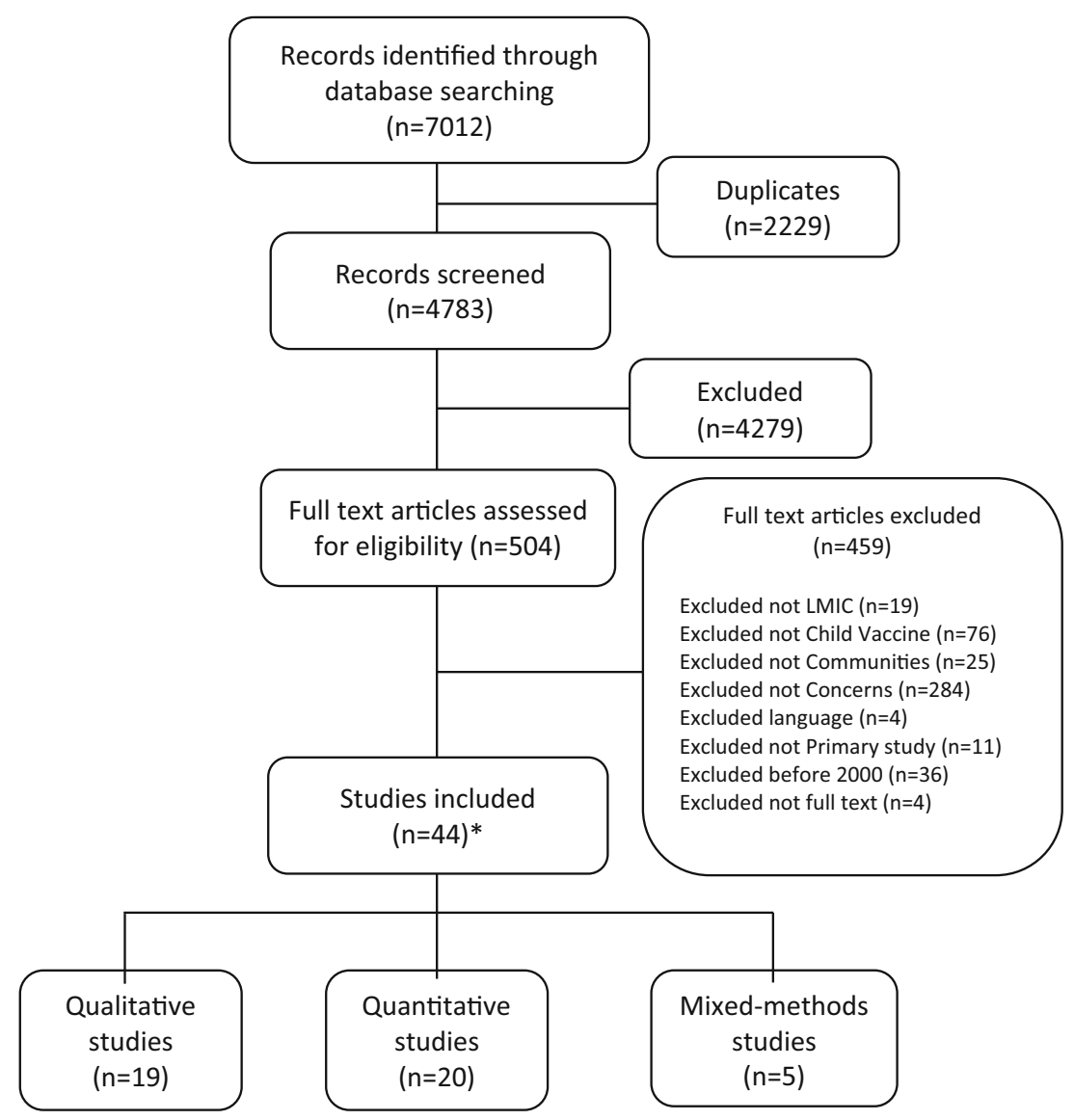

* One study was reported in two published articles (Logullo 2008)

Table 1 Ten most frequently reported concerns (as number of quotes) about vaccination from studies with qualitative data in the systematic review on concerns about vaccination in low- and middle-income countries

\begin{tabular}{lll}
\hline Issue & Concern $^{\text {a }}$ & Number of quotes \\
\hline Harm & 1.2 Believes cause diseases/general harm/adverse effects & 43 \\
Trust & 2.1 Conspiracy theory/distrust in medical community & 26 \\
Harm & 1.4 Concern with side effects after vaccination & 25 \\
Trust & 2.3 Religious reasons & 17 \\
Trust & 2.2 Lack of trust in vaccines effectiveness & 16 \\
Health system & 3.3 Health staff are unpleasant/untrained & 15 \\
Harm & 1.8 Vaccines are provided at too young age/too many & 13 \\
Health system & 3.5 Concern with quality of vaccines & 12 \\
Health system & 3.1 Concern with cost/access & 8 \\
Other & 4.2 Social stigma for mothers that vaccinate & 7 \\
\hline
\end{tabular}

${ }^{a}$ Concerns are classified according to the items in Table 1 in the Online Resource

\section{Perceived concerns about vaccination}

A total of 213 quotes reported individuals' and communities' vaccination concerns and 56 measures of their frequency were extracted from quantitative studies. The ten most reported concerns in qualitative studies are shown in Table 1. Table 2 presents data extracted from quantitative studies included in this review (odds ratios of concerns and outcomes are shown in Table 7 of the Online Resource). The geographical distribution of concerns based on data extracted from qualitative studies is shown in Fig. 2. 


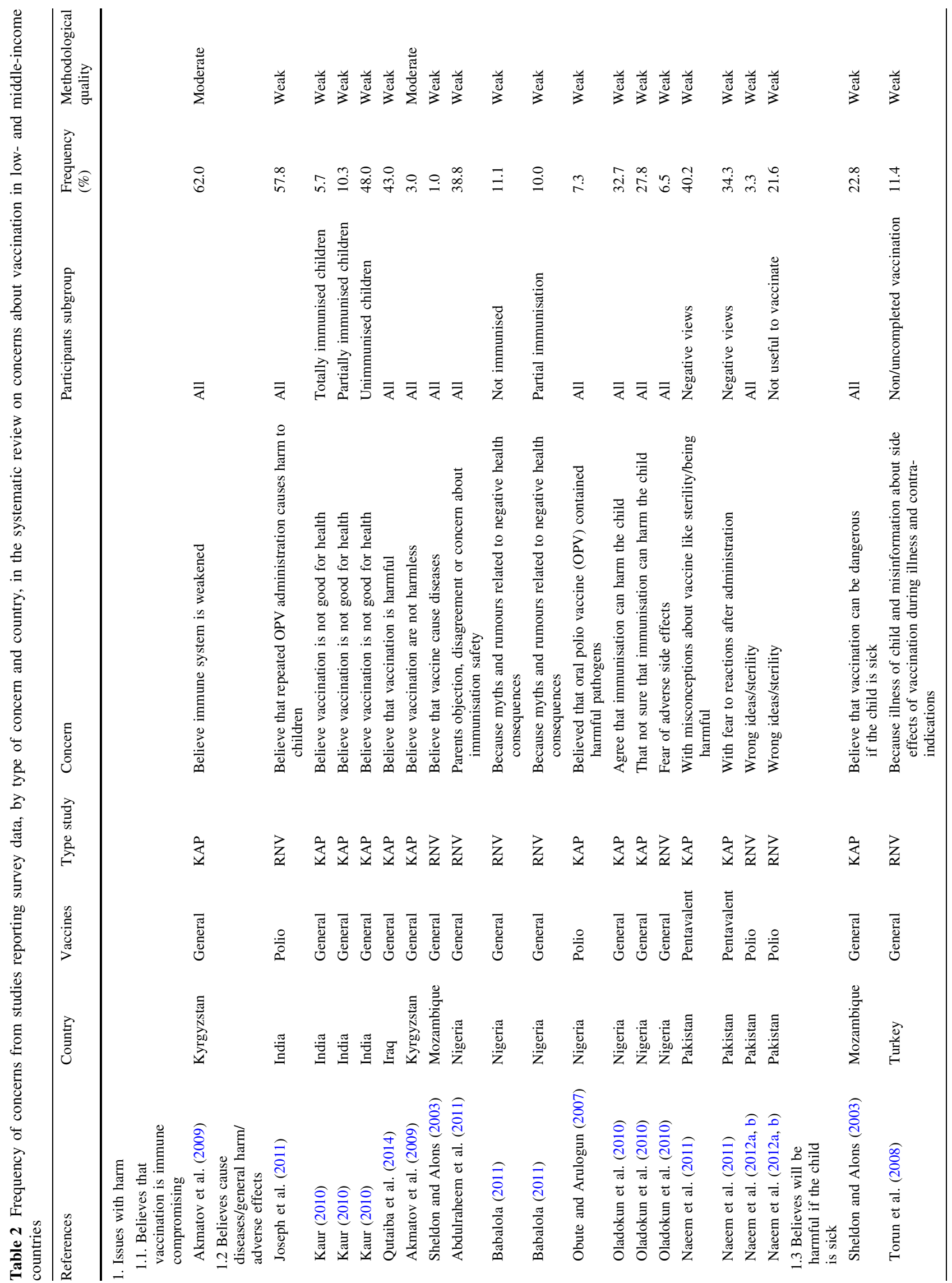




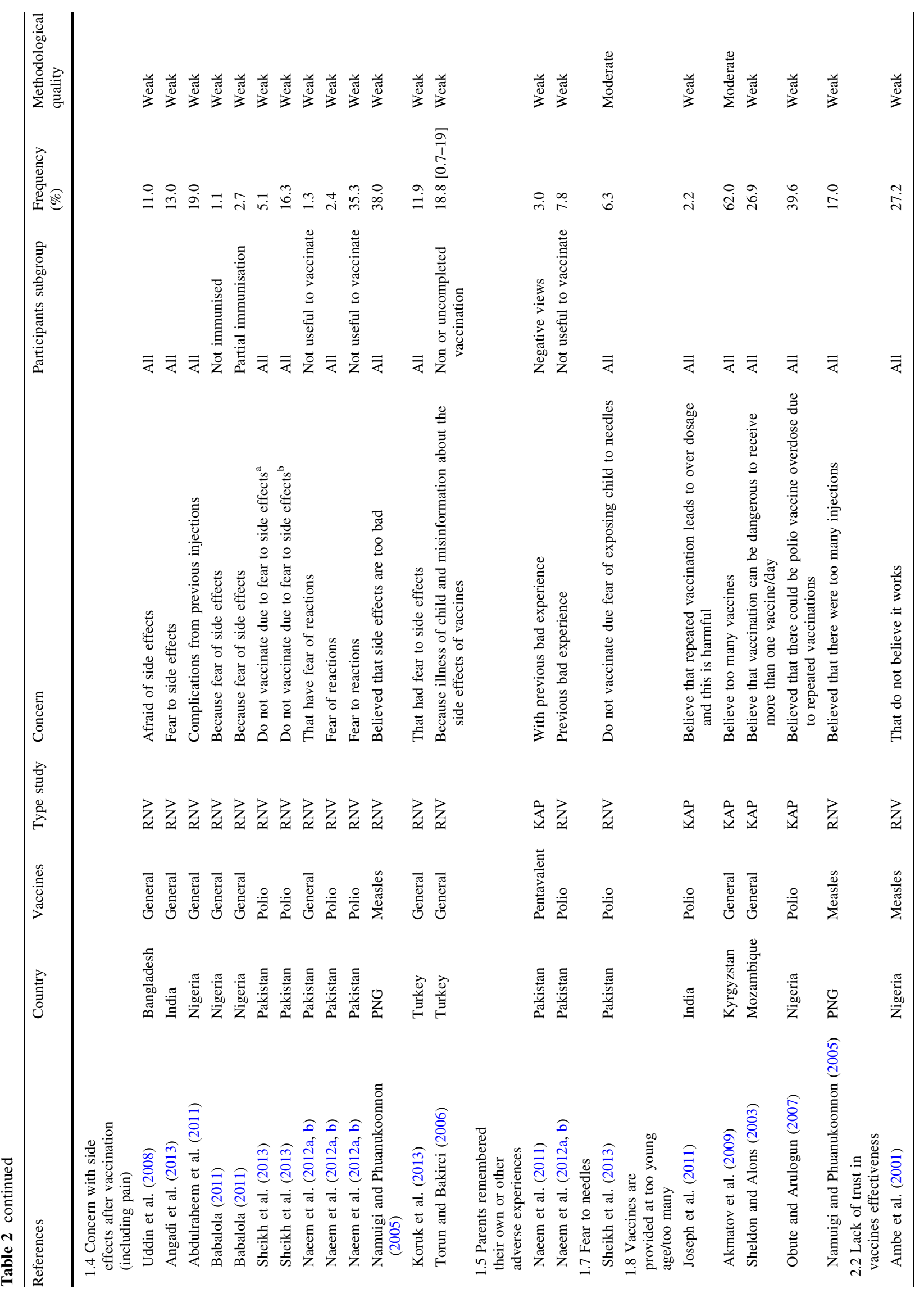




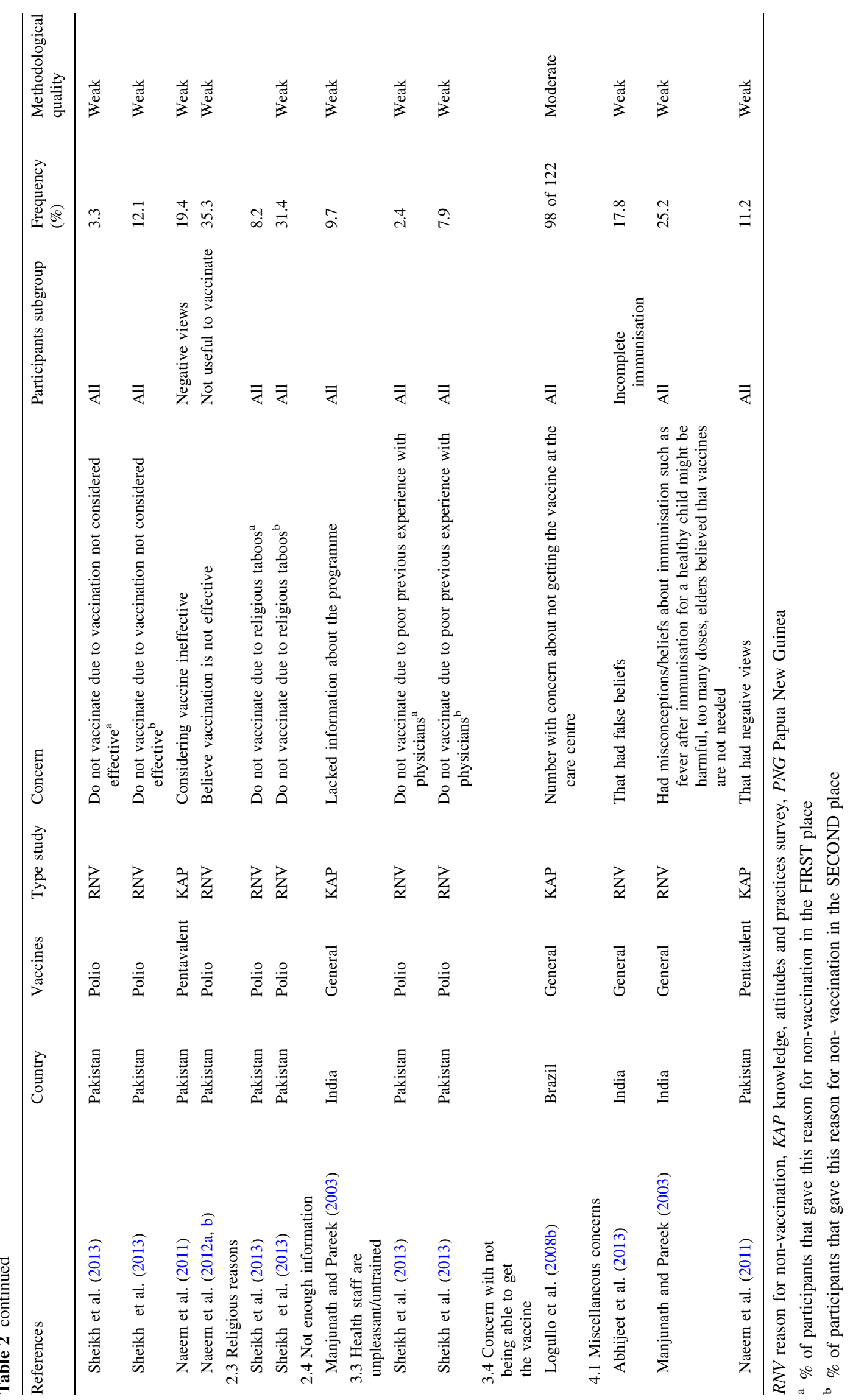




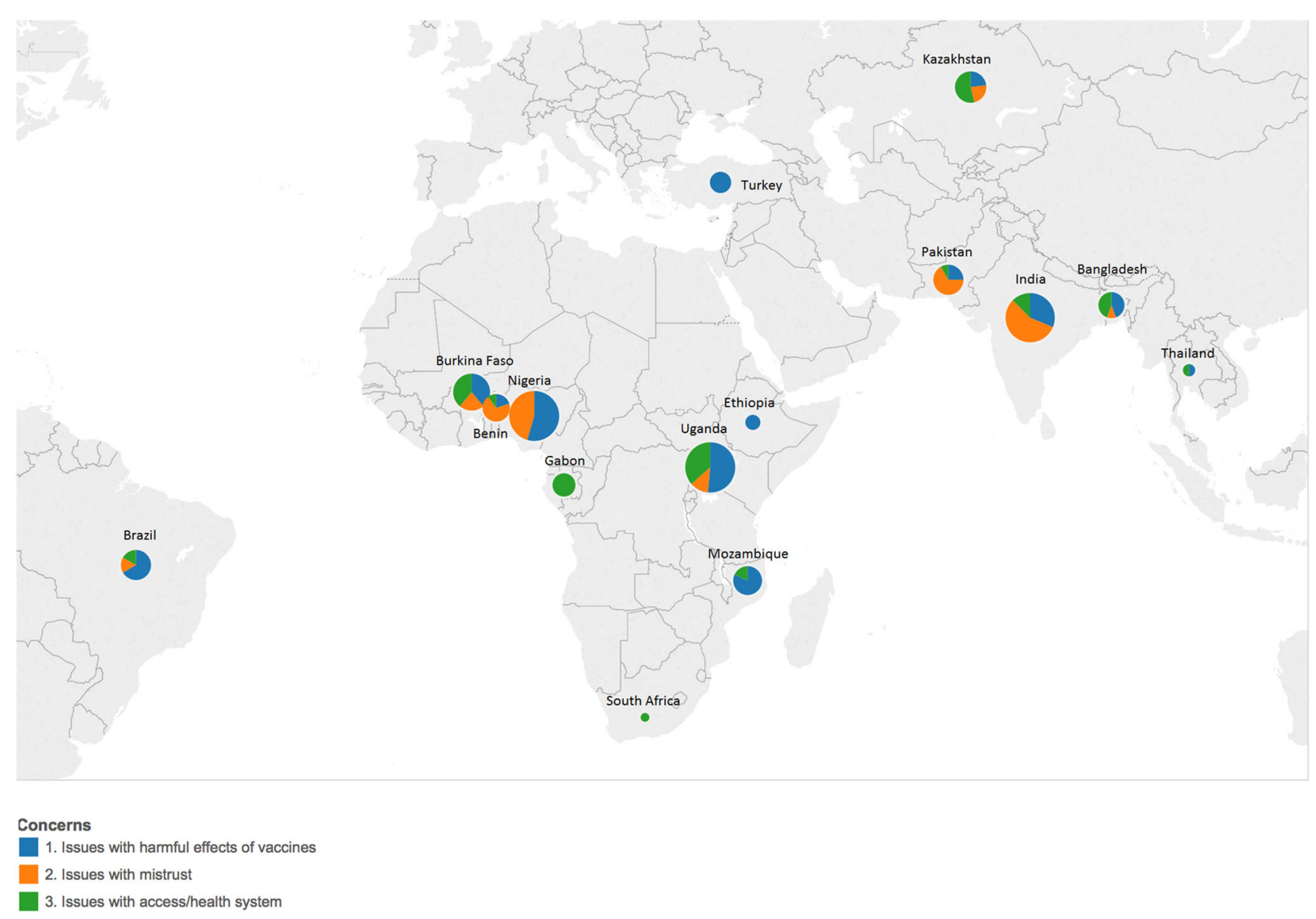

Fig. 2 Map of the number of quotes on concerns by country and type of concern from qualitative studies in the systematic review on concerns about vaccination in low- and middle-income countries

Issues with harmful effects of vaccination

The perception of potential harms of vaccines was the most frequently reported concern in qualitative studies. The belief that vaccines could produce serious negative effects on children's health was reported in all three continents and in nine of the 15 countries which reported this concern. Their frequency measured through surveys in the general population showed that up to $43 \%$ of the respondents believed that vaccines were harmful (Qutaiba et al. 2014). A study conducted in Kyrgyzstan estimated that even though $3 \%$ of the respondents believed that vaccinations were not harmless, $62.0 \%$ believed that the immune system is weakened after vaccination (Akmatov et al. 2009). Results from Nigeria showed similar results with $32.7 \%$ of the respondents agreeing that immunisation can harm the child (Oladokun et al. 2010) and $7.3 \%$ reporting specific concerns about polio vaccine (Obute and Arulogun 2007). Concerns about the potential harm of vaccines were more frequent among parents with unimmunised children or with general negative views about vaccination (Kaur 2010;
Naeem et al. 2011). Parents from India, Mozambique, Nigeria and Pakistan were asked about the reasons for nonvaccinating their children. Potential harm of vaccines was the first reason raised by $57.8 \%, 1.0 \%, 38.8 \%$ and $3.3 \%$ of all parents, respectively (Joseph et al. 2011; Sheldon and Alons 2003; Abdulraheem et al. 2011; Naeem et al. 2012b).

Some study authors suggested that fear of serious adverse effects could be a consequence of past experiences with adverse events following immunisation (AEFI) which may be more or less easily attributed to the vaccination event. As one participant in a FGD explained: "At one time our neighbour in a 'rural geographical area' immunised a child in the morning and by $5.00 \mathrm{p} . \mathrm{m}$. the child was dead. From that time I fear taking children for immunisation and all my children are not immunised" (Babirye et al. 2011). In another case: "Sometimes after immunisation children get fever and spend the whole night crying so the health worker must tell the mother in advance what will happen to the baby, that the baby might become weak, or get a fever or the injection is painful so he will cry a lot" (Babirye et al. 2011). 
Nine studies reported concerns related to minor side effects, to which they attributed a significant impact on vaccination behaviour. Perry et al. concluded in their study in Bangladesh: "a number of mothers mentioned that their children had developed fever, swelling at the injection site, or had otherwise become sick after immunisation and they, therefore, did not want to take their children back for any further immunisations" (Perry et al. 2007). Quantitative studies found that this reason was less prominent [between 1.1 and $18.8 \%$ among people with negative views about vaccination or with a child partially or totally unimmunised (Babalola 2011; Naeem et al. 2012b; Torun et al. 2008)]. The fact that vaccines produced side effects, such as fever, after vaccination also strengthened the belief that vaccines could be harmful: "If you vaccinate the child and then on the following day it has a hot body, then his mother no longer wants him to be vaccinated. She tells herself that this is due to the vaccination" (Sia et al. 2011).

Some attributed effects of vaccination were based on rumours with little or no support from evidence. Babalola et al. (Nigeria) described that "there (were) widespread rumours about serious health consequences of immunisation that are believed to come from credible sources and have the support of respectable people in the community" (Babalola 2011). Although a wide variety of rumours about vaccination were reported in different settings, vaccination causing sterility was one of the most frequently reported. Khowaja et al. concluded in their study in Pakistan that "most of the parents thought that the polio vaccine caused sterility in adulthood" (Khowaja et al. 2012). $3.3 \%$ of the people surveyed in one study in Pakistan reported fears that vaccines produced sterility as their main reason for not vaccinating their children. This proportion went up to $21.6 \%$ and $40.2 \%$ among those who did not consider having their children vaccinated as useful and who had negative views about vaccination, respectively (Naeem et al. 2012b).

Other reported concerns were the high number of vaccines administered at once and a widespread rumour that a sick child cannot be vaccinated, the latter shared by parents and health professionals. A survey in Kyrgyzstan estimated that up to $62 \%$ of parents were worried about the high number of vaccines that their children were receiving (Akmatov et al. 2009) and $26.9 \%$ of the people surveyed in Mozambique believed that receiving more than one vaccine per day could be dangerous (Sheldon and Alons 2003).

These concerns have the potential to affect parents' behaviour in terms of adherence to vaccination as noted by Braka in Uganda: "Experiences with AEFI and concerns about vaccine safety negatively affected caretakers' decisions to vaccinate their children, notably in rural areas" (Braka et al. 2012). Quantitative studies also reported similar findings. A study in Nigeria found that the odd of incomplete vaccination was 1.86 (CI $95 \% 1.63$ to 2.22) times higher among children whose parents had concerns about vaccination safety (Abdulraheem et al. 2011). In contrast, having heard about deaths due to vaccination or believing that vaccines produce diseases were not associated with incomplete vaccination in Colombia (Tirado Otávaro and Moreno Uribe 2006). Having a complication from a previous injection or having fear of injections were associated with missed opportunities and delays in measles vaccination, respectively (Abdulraheem et al. 2011; Logullo et al. 2008b).

\section{Issues with programme distrust}

We include in this section concerns related to lack of trust in vaccines or immunisation programmes based on the belief that vaccines are part of a global conspiracy against some communities or religious beliefs (e.g. Muslims, darkskinned people or Africans). Despite this being the second most frequently reported concern in qualitative studies, we could not find any quantitative estimate of it in quantitative studies.

As one health provider explained in an interview: "Each time, you will hear newer and more and more weird things about the vaccine ... They can stretch the limits of imagination... Last time there was a strong rumour that the polio vaccine is prepared by the Jews and America is using them to finish Muslims" (Chaturvedi et al. 2009). Several participants saw vaccines as a tool of "Western powers" to control or harm their communities (Khowaja et al. 2012; Olufowote 2011). Some say that this is a strategy to reduce the capacity to procreate so that there will be birth spacing. For others, vaccines were "poisons created by white people to harm us and to do experiments on us in giving us diseases" (Fourn et al. 2009) or they "are intended to kill off Africans" (Braka et al. 2012). This view could also be supported and promoted by community and religious leaders: a Nigerian pastor admitted in an interview “(...) to have voiced his constituents' beliefs that the polio vaccinations were part of a Western plot to depopulate developing nations, particularly Muslim communities" (Olufowote 2011).

Religious beliefs were another source of lack of trust in vaccines. An example of this belief was that vaccination was against the will of God; vaccinating a child is like making a "deal with the Devil"; the act of vaccination was seen as "the work of the white witch doctor, contrary to biblical scriptures" (Fourn et al. 2009). Religious beliefs also affect the perception of effectiveness among faithful parents: "Polio is due to mammy water (water mermaid). The solution is not immunisation. The solution is to sacrifice to the mermaid by 12 midnight in any river close to 
where the child was born, on the night of the child's birth. Once this is done, the child can never have polio" (Etokidem and Wondifon 2013). Religious taboos were given as the first reason for non-vaccination in $8.2 \%$ and as the second reason in $31.4 \%$ of people surveyed in Pakistan (Sheikh et al. 2013).

One concern was actually rooted in a 'public health' rationale, reported by Khowaja as a quote from an interview in Pakistan: "Why do the government and health system give so much emphasis to polio vaccine? There are so many other diseases that should be addressed first. There must be some other reason (negative reason) for their giving so much importance to polio vaccine" (Khowaja et al. 2012).

\section{Health system issues}

Regarding health system issues, nine studies reported people's anxiety about health care workers being unpleasant. One mother participating in a FGD in Burkina Faso explained: "The health care worker shouts, is arrogant, argues, makes a fuss, is ill-tempered, uses awkward words and scolds you" (Sia et al. 2011). As concluded by Perry et al. in their study in Bangladesh: "The fear of being 'scolded' by the vaccinator after losing the immunisation card (a not uncommon event), and the necessity of having to pay to obtain a new one" was one of the major barriers to access vaccination services (Etokidem and Wondifon 2013; Perry et al. 2007). Some mothers feared going to the health facility for vaccination if they did not have a good enough "baby shawl" to carry the baby. They have reported being harassed by nurses as a consequence of that (Babirye et al. 2011). Sheikh et al. reported that $2.4 \%$ and $7.9 \%$ of people surveyed reported poor previous experience with physicians as the first and second reasons for not vaccinating their children, respectively (Sheikh et al. 2013)

Concerns related to costs of accessing immunisation services were also reported. Costs of the immunisation card or transport or "under the table" payments represented some of the sources of anxiety for caregivers. One mother explained during an in-depth interview in Gabon: "Somebody, who has an outstanding debt [hospital bill] for example, if he does not have the financial means to settle the debts, he cannot come back. Some people are actually afraid to come back" (Schwarz et al. 2009). They also worried about spending some money to get to the health facility and then not being able to get the vaccine. Frequent vaccine stock-outs lessen the confidence of parents on the health system (Schwarz et al. 2009).

Participants in qualitative studies also raised concerns related to the quality of vaccines administered at health facilities. Several issues were reported regarding vaccines being expired (Babirye et al. 2011; Braka et al. 2012), weak cold chain (Braka et al. 2012; Fowler et al. 2007; Khowaja et al. 2012) or health workers reusing syringes (Dasgupta et al. 2008). Concerns with vaccines purchased by the government were reported in Kazakhstan and Uganda. Fowler et al. concluded in their study in Kazakhstan: "The most widespread concern among key informants was that the government would purchase low quality vaccines that could put children's health at risk" (Fowler et al. 2007).

\section{Other issues}

Canavati found a specific concern from migrants in Thailand during a series of FGD. They were worried of being arrested if they attended the clinic to vaccinate their children. As a father explained: "We are afraid of the police. There are several checkpoints from our place to the vaccine site and we can get arrested anytime (...). The only reason we would risk accessing a Thai clinic is when our child is very ill because under those circumstances the Tai police would not do anything to us" (Canavati et al. 2011).

\section{Discussion}

We have exposed and synthesised evidence on individual and community concerns about childhood vaccination and have highlighted the most frequently reported concerns in qualitative studies and prevalence rates from quantitative studies. We have described the whole range of caregivers' concerns about vaccination and their variations across geographical areas and cultural settings.

Concerns about harmful effects of vaccination seemed to be the most common factor influencing vaccination behaviour, followed by mistrust of vaccination programmes. Other concerns were less prevalent. Fear of side effects, fear of sterility or disability after vaccination or concerns about receiving too many vaccines at once were some of the most commonly reported. Health system issues were also widely reported as source of concerns. The lack of trust on vaccine effectiveness, concerns about health staff being unpleasant or concerns about not being able to get the vaccine at the health facility were reasons reported to avoid vaccination in some cases. This large array of issues only worsens existing programmatic and health systems challenges (Favin et al. 2012) of childhood vaccination.

Although there were concerns that were spread across most settings (e.g. the belief that vaccines could produce serious negative effects on children's health), they were highly influenced by cultural, religious or social beliefs. For instance, concerns about vaccines being part of a 
conspiracy to harm specific groups were common among Muslim communities and worries about the quality or cost of the services provided were more reported in studies from African countries.

A number of systematic reviews addressed concerns to vaccination or similar issues. Some of them are restricted to only one or a few vaccines (Brown et al. 2010) or to nonchildhood vaccines (European Centre for Disease Prevention and Control 2013; Hendry et al. 2013; Trim et al. 2012) or focus on developed geographical areas (European Centre for Disease Prevention and Control 2013; Falagas and Zarkadoulia 2008) or include only qualitative studies (Mills et al. 2005a). Rainey et al. 2011 covers a relatively short and old time period (1999-2009), limiting the evidence to only published studies and explores "reasons and factors" (rather than focusing on concerns) related to nonvaccination and under-vaccination in general. A similar approach was used by Favin et al. (2012). Larson et al. (2014) provided more recent evidence (2007-2012) describing the frequencies of studies reporting concerns rather than the actual descriptions of concerns and their reasons among the caregivers (Larson et al. 2014).

There are reasonable doubts that all potentially relevant issues influencing vaccine hesitancy have been identified or thoroughly investigated (Mills et al. 2005b; Larson et al. 2014). Indeed, a recent review of studies conducted in high income countries showed that although reasons why parents refuse to vaccinate their children have been widely studied, little is known about the factors that motivate parents to vaccinate (Williams 2014). In their comparative analysis of concerns about vaccination in qualitative and quantitative studies, Mills et al. concluded that surveys failed to capture the whole spectrum of concerns identified in previously published qualitative studies. Concerns identified in qualitative studies were not properly represented in quantitative studies as questionnaires did not include relevant items drawn from qualitative research. One explanation may be that, as we realised, none of the quantitative studies estimating the frequency of different concerns in LMIC was actually specifically designed to assess concerns; rather they were surveys examining wider issues related to the uptake of vaccination, which included concerns.

Indeed, quantitative studies failed to capture many issues related to concerns about vaccination identified in qualitative studies in our review (Table 8 in the Online Resource). It is clear that surveys focused their questions on concerns related to the potential harms of vaccination. Fewer studies reported quantitative data of issues related with distrust. For example, although concerns about vaccines being part of a Western plot against Muslims or vaccines containing pig's blood were consistently reported in qualitative studies, only five of the 19 surveys provided some quantitative estimates about it. Even a more extreme situation was found regarding health system issues: only two studies reported quantitative data on this group of concerns. Concerns about the quality of vaccines provided at the health facility or concerns about health workers being unpleasant were neglected in the surveys included.

Several reviews of interventions to improve vaccination coverage report on strategies addressing concerns. A review focusing on LMIC (Oyo-Ita et al. 2011) identified three trials directly or indirectly related to concerns. These studies were of moderate quality and showed promising effects on coverage rates; two of them were the only two studies included in the review by Saeterdal et al. (2014). The systematic review of Kaufman et al. (2013) included studies which assessed face-to-face communication directed to individual parents and concluded that the low quality evidence available did not seem to make any difference on vaccination status, knowledge or understanding of vaccination. In this sense, it is deeply disappointing that Sadaf et al. (2013) could only conclude that their systematic review "did not reveal any convincing evidence on effective interventions to address parental vaccine hesitancy and refusal". Most of the research on interventions dealt with reminders, recalls and provider-based interventions and alike, but hardly any intervention addressed vaccine refusal or changes in attitudes.

Not surprisingly, no strong recommendations could be issued by SAGE in terms of interventions to address vaccine hesitancy. Recognising that no single intervention addresses all instances of vaccine hesitancy, recommending generic marketing and communication concepts [such as "focusing on benefits of immunisation, drawing on emotional values, focusing on 1 or 2 key messages, employing proactive messaging" (WHO 2014c)] fall very short of what could be expected. We believe that careful consideration of the concerns that we have exposed in this review could inform some more concrete recommendations till enough evidence on the effects of interventions to address concerns is available.

The findings in this review are subject to a number of limitations. We searched only for papers and reports written in English, French, Spanish or Portuguese. We cross-checked previously identified relevant studies to minimise the chances that relevant papers would have been excluded. Single study inclusion decisions could have missed studies. However, we believe that double, independent decisions on inclusion would not have substantially changed the conclusions of this review. Selective reporting in both qualitative and quantitative studies could not be ruled out. Because we could not find any study with the primary aim of describing concerns, it is likely that the prevalence of concerns extracted from 
quantitative studies have limited external validity and that the literature tends to underreport them.

\section{Conclusions}

Highly influenced by social, cultural and religious beliefs, concerns about vaccinations are prevalent, and impact the vaccination status of populations.

In the research domain, there is a disconnection between quantitative and qualitative research which misses the opportunity to quantify what is reported in qualitative studies across different strata of populations and geographical settings. There is an important imbalance where research describing concerns is far more abundant than research testing interventions to address them. Assessing interventions to address concerns remains a neglected research area.

We encourage the global health community including WHO to continue its work on vaccine hesitancy, prioritising research which explains the mechanisms of vaccine hesitancy and research which tests interventions to address it. Appropriate funding should be made available for this work. In the absence of robust evidence, guidance can still be produced to assist the global community and health authorities of various countries to address concerns on childhood vaccination.

Acknowledgments This study was conducted as part of the project "Evidence Portal-Immunization" funded by the International Initiative for Impact Evaluation (3iE) and the Global Development Network (GDN). We thank John Eyers for developing the search strategy and to Mitchell G. Weiss for his comments of the manuscript.

\section{References}

Abdulraheem IS, Onajole AT, Jimoh AAG, Oladipo AR (2011) Reasons for incomplete vaccination and factors for missed opportunities among rural Nigerian children. J Public Health Epidemiol 3(4):194-203

Abhijeet I, Dixit JV, Deven D (2013) Reasons behind incomplete immunization: a cross sectional study at Urban Health Centre of Government Medical College, Aurangabad. Natl J Community Med 4(2):353-356

Akmatov MK, Mikolajczjk RT, Kretzschmar M, Kramer A (2009) Attitudes and beliefs of parents about childhood vaccinations in post-soviet countries the example of Kyrgyzstan. Pediatr Infect Dis J 637-640. doi:10.1097/INF.0b013e3181966401

Ambe JP, Omotara BA, Mandu Baba M (2001) Perceptions, beliefs and practices of mothers in sub-urban and rural areas towards measles and measles vaccination in Northern Nigeria. Trop Dr 31(2):89-90

Angadi MM, Jose AP, Udgiri R, Masali KA, Sorganvi V (2013) A study of knowledge, attitude and practices on immunization of children in urban slums of bijapur city, karnataka, India. J Clin Diagn Res 7(12):2803-2806

Asgary R, Kam E, Mumm L, Arole S (2011) Evaluating immunization rates and barriers to immunization for children 1 to 5 years old in rural India. Am J Trop Med Hyg 60th Annu Meet Am Soc Trop Med Hyg ASTMH 2011 Phila PA US Conf Start 20111204 Conf End 20111208 Conf Publ (var.pagings) 85(6 suppl. 1):34

Babalola S (2011) Maternal reasons for non-immunisation and partial immunisation in northern Nigeria. J Paediatr Child Health 47:276-281. doi:10.1111/j.1440-1754.2010.01956.x

Babirye JN, Rutebemberwa E, Kiguli J, Wamani H, Nuwaha F, Engebretsen IM (2011) More support for mothers: a qualitative study on factors affecting immunisation behaviour in Kampala, Uganda. BMC Public Health 723. doi:10.1186/1471-2458-11-723

Bedford H, Elliman D (2000) Concerns about immunisation. Br Med J 320:240-243

Bedford J, Singh A, Ponferrada MB, Eldred L (2013) Access to health services: analysing non-financial barriers in Ghana, Bangladesh, Vietnam and Rwanda using qualitative methods. UNICEF

Bosch-Capblanch X, Banerjee K, Burton A (2012) Unvaccinated children in years of increasing coverage: how many and who are they? Evidence from 96 low- and middle-income countries. Trop Med Int Health 697-710. doi:10.1111/j.1365-3156.2012.02989.x

Braka F, Asiimwe D, Soud F, Lewis RF, Makumbi I, Gust D (2012) A qualitative analysis of vaccine safety perceptions and concerns among caretakers in Uganda. Matern Child Health J 1045-1052. doi:10.1007/s10995-011-0826-5

Brown KF, Kroll JS, Hudson MJ, Ramsay M, Green J, Long SJ, Vincent CA, Fraser G, Sevdalis N (2010) Factors underlying parental decisions about combination childhood vaccinations including MMR: a systematic review. Vaccine 4235-4248. doi:10.1016/j.vaccine.2010.04.052

Canavati S, Plugge E, Suwanjatuporn S, Sombatrungjaroen S, Nosten F (2011) Barriers to immunization among children of migrant workers from Myanmar living in Tak province, Thailand. Bull World Health Organ 528-531. doi:10.2471/B1t.10.084244

Chaturvedi S, Dasgupta R, Adhish V, Ganguly KK, Rai S, Sushant L, Srabasti S, Arora NK (2009) Deconstructing social resistance to pulse polio campaign in two North Indian districts. Indian Pediatr 963-974

Critical Appraisal Skills Programme (CASP) (2014) CASP qualitative research checklist 31.05.13, Oxford. http://media.wix.com/ugd/ dded87_29c5b002d99342f788c6ac670e49f274.pdf. Accessed Feb 2014

Dasgupta R, Chaturvedi S, Adhish SV, Ganguly KK, Rai S, Sushant L, Arora NK (2008) Social determinants, polio 'endgame': a qualitative study in high risk districts of India. Indian Pediatr 45:357-365

Dugas M, Dube E, Kouyate B, Sanou A, Bibeau G (2009) Portrait of a lengthy vaccination trajectory in Burkina Faso: from cultural acceptance of vaccines to actual immunization. BMC Int Health Hum Rights S9. doi:10.1186/1472-698X-9-S1-S9

Effective Public Health Practice Project (2010) Quality assessment tool for quantitative studies. http://www.ephpp.ca/PDF/Quality\% 20Assessment\%20Tool_2010_2.pdf. Accessed Feb 2014

Etokidem AJ, Ndifon W (2013) Myths and misconceptions as barriers to uptake of immunization services in Nigeria. $\mathrm{J}$ Vaccines Vaccination 4(7):204. doi:10.4172/2157-7560.1000204

European Centre for Disease Prevention and Control (2013) Review of scientific literature on drivers and barriers of seasonal influenza vaccination coverage in the EU/EEA. Stockholm

Falagas ME, Zarkadoulia E (2008) Factors associated with suboptimal compliance to vaccinations in children in developed countries: a systematic review. Curr Med Res Opin 1719-1741. doi:10.1185/03007990802085692

Favin M, Steinglass R, Fields R, Banerjee K, Sawhney M (2012) Why children are not vaccinated: a review of the grey literature. Int Health 229-238. doi:10.1016/j.inhe.2012.07.004

Figueiredo GLA, Pina JC, Tonete VLP, de Lima RAG, de Mello DF (2011) Experiences of families in the immunization of Brazilian 
children under two years old. Rev Lat-Am Enferm 598-605. doi:10.1590/S0104-11692011000300020

Fourn L, Haddad S, Fournier P, Gansey R (2009) Determinants of parents' reticence toward vaccination in urban areas in Benin (West Africa). BMC Int Health Hum Rights S14. doi:10.1186/ 1472-698X-9-S1-S14

Fowler GL, Kennedy A, Leidel L, Kohl KS, Khromava A, Bizhanova G, Shui I, Gust D (2007) Vaccine safety perceptions and experience with adverse events following immunization in Kazakhstan and Uzbekistan: a summary of key informant interviews and focus groups. Vaccine 3536-3543. doi:10.1016/ j.vaccine.2007.01.082

Helman CG, Yogeswaran P (2004) Perceptions of childhood immunisations in rural Transkei-a qualitative study. SAMJ South Afr Med J 94(10):835-838

Hendry M, Lewis R, Clements A, Damery S, Wilkinson C (2013) "HPV? Never heard of it!": a systematic review of girls' and parents' information needs, views and preferences about human papillomavirus vaccination Vaccine 31:5152-5167. doi:10.1016/ j.vaccine.2013.08.091

Higgins J, Green S (2011) Cochrane handbook for systematic reviews of interventions version 5.1.0. The Cochrane Collaboration

Institute of Medicine (IOM) (2012) The childhood immunization schedule and safety. Stakeholder concerns, scientific evidence and future

Jackson N, Waters E, Guidelines for Systematic Reviews in Health P and Public Health T (2005) Criteria for the systematic review of health promotion and public health interventions. Health Promot Int 367-374. doi:10.1093/heapro/dai022

Joseph N, Subba SH, Nelliyanil M, Kotian SM, Haridath AC, Kishor N, Attavar S, Poornima P, Rane DV, Chaithali H, Husain J (2011) A study of the knowledge and attitude towards pulse polio immunization in semi urban areas of South India. Australas Med J 4(2):81-86. doi:10.4066/AMJ.2011.532

Kata A (2010) A postmodern Pandora's box: anti-vaccination misinformation on the Internet. Vaccine 28:1709-1716. doi:10. 1016/j.vaccine.2009.12.022

Kaufman J, Synnot A, Ryan R, Hill S, Horey D, Willis N, Lin V, Robinson P (2013) Face to face interventions for informing or educating parents about early childhood vaccination. Cochrane Database Syst Rev CD010038. doi:10.1002/14651858.CD010038. pub2

Kaur SM (2010) Knowledge and attitude of fathers of 12-24 months of age children towards the practice of immunization in Amritsar. Indian J Matern Child Health 12(3):9

Khowaja AR, Khan SA, Nizam N, Omer SB, Zaidi A (2012) Parental perceptions surrounding polio and self-reported non-participation in polio supplementary immunization activities in Karachi, Pakistan: a mixed methods study. Bull World Health Organ 822-830. doi:10.2471/BLT.12.106260

Kolendorf K, Aaby P, Westergaard S, Deckert T (1978) Absorption, effectiveness and side effects of highly purified porcine NPHinsulin preparations (Leo). Eur J Clin Pharmacol 117-124. doi:10.7860/JCDR/2013/6565.3763

Koruk I, Simsek Z, Koruk ST (2013) A case of childhood vaccination barrier: migrant and seasonal farmworkers. Turk J Med Sci 424-429. doi:10.3906/sag-1112-20

Larson HJ, Cooper LZ, Eskola J, Katz SL, Ratzan S (2011) Addressing the vaccine confidence gap. Lancet 526-535. doi:10.1016/S0140-6736(11)60678-8

Larson HJ et al (2013) Measuring vaccine confidence: analysis of data obtained by a media surveillance system used to analyse public concerns about vaccines. Lancet Infect Dis 13:606-613. doi:10. 1016/s1473-3099(13)70108-7

Larson HJ, Jarrett C, Eckersberger E, Smith DM, Paterson P (2014) Understanding vaccine hesitancy around vaccines and vaccination from a global perspective: a systematic review of published literature, 2007-2012. Vaccine 2150-2159. doi:10. 1016/j.vaccine.2014.01.081

Logullo P, Barbosa de Carvalho H, Saconi R, Massad E (2008a) Factors affecting compliance with the measles vaccination schedule in a Brazilian city. Sao Paulo Med J 166-171

Logullo P, de Carvalho HB, Saconi R, Massad E (2008b) Fear of injections is a reason for not to vaccinate their children, say caretakers. Vaccine 141-143. doi:10.1016/j.vaccine.2007.09.075

Manjunath U, Pareek RP (2003) Maternal knowledge and perceptions about the routine immunization programme-a study in a semiurban area in Rajasthan. Indian J Med Sci 57(4):158-163

Mills E, Jadad AR, Ross C, Wilson K (2005a) Systematic review of qualitative studies exploring parental beliefs and attitudes toward childhood vaccination identifies common barriers to vaccination. J Clin Epidemiol 1081-1088. doi:10.1016/j.jclinepi.2005.09.002

Mills E, Montori VM, Ross CP, Shea B, Wilson K, Guyatt GH (2005b) Systematically reviewing qualitative studies complements survey design: an exploratory study of barriers to paediatric immunisations. J Clin Epidemiol 1101-1108. doi:10. 1016/j.jclinepi.2005.01.014

Moher D, Liberati A, Tetzlaff J, Altman DG, The PRISMA Group (2009) Preferred reporting items for systematic reviews and meta-analyses: the PRISMA statement. PLoS Med 6. doi:10. 1371/journal.pmed.100009

Naeem M, Adil M, Zia-Ul-Islam Khan M, Abbas SH (2011) Coverage and causes of missed BCG vaccination: a user perspective study. J Med Sci 19(3):122-125

Naeem M, Abbas SH, Gul S, Adil M, Khan MZUI, Khan MS (2012a) Causes of immunization failure in DPT vaccination in urban and rural areas of Peshawar. J Med Sci 20(4):187-191

Naeem M, Khan MZ, Muhammad A, Abbas SH, Ayasha K, Khan MU, Naz SM (2012b) Coverage and causes of non immunization in National Immunization Days for polio; a consumer and provider perspective study in Peshawar. J Postgrad Med Inst 26(1):48-54

Namuigi P, Phuanukoonnon S (2005) Barriers to measles immunization: the beliefs and attitudes of caregivers in Goroka, Eastern Highlands Province, Papua New Guinea. P N G Med J 48(3-4):183-187

Obute JA, Arulogun OS (2007) Parents' awareness and perception of the polio eradication programme in Gombe Local Government Area, Gombe State, Nigeria. Int J Health Promot Educ 81-86

Oladokun RE, Adedokun BO, Lawoyin TO (2010) Children not receiving adequate immunization in Ibadan, Nigeria: what reasons and beliefs do their mothers have? Niger J Clin Pract 173-178

Olufowote JO (2011) Local resistance to the global eradication of polio: newspaper coverage of the 2003-2004 vaccination stoppage in northern Nigeria. Health Commun 743-753. doi:10.1080/10410236.2011.566830

Oyo-Ita A, Nwachukwu CE, Oringanje C, Meremikwu MM (2011) Interventions for improving coverage of child immunization in low- and middle-income countries. Cochrane Database Syst Rev CD008145. doi:10.1002/14651858.CD008145.pub2

Perry H, Nurani S, Abdul Quaiyum M, Jinnah SA, Sharma A (2007) Barriers to immunization among women and children living in slums of Zone 3 of Dhaka City, Bangladesh. A qualitative assessment. International Centre for Diarrhoeal Disease Research, Bangladesh [ICDDR, B]

Qutaiba BA-1O, Bahari MB, Al-Qazaz HK, Salih MR, Jamshed SQ, Elkalmi RM (2014) Are parents' knowledge and practice regarding immunization related to pediatrics' immunization compliance? A mixed method study. BMC Pediatr 20. doi:10. 1186/1471-2431-14-20

Rainey JJ, Watkins M, Ryman TK, Sandhu P, Bo A, Banerjee K (2011) Reasons related to non-vaccination and under-vaccination 
of children in low and middle income countries: findings from a systematic review of the published literature, 1999-2009. Vaccine 8215-8221. doi:10.1016/j.vaccine.2011.08.096

Sadaf A, Richards JL, Glanz J, Salmon DA, Omer SB (2013) A systematic review of interventions for reducing parental vaccine refusal and vaccine hesitancy. Vaccine 4293-4304. doi:10.1016/ j.vaccine.2013.07.013

Saeterdal I, Lewin S, Austvoll-Dahlgren A, Glenton C, MunabiBabigumira S (2014) Interventions aimed at communities to inform and/or educate about early childhood vaccination. Cochrane Database Syst Rev CD010232. doi:10.1002/14651858. CD010232.pub2

SAGE Working Group on Vaccine Hesitancy (2013a) A model of determinants of vaccine hesitancy. http://www.who.int/ immunization/sage/meetings/2014/october/1_Report_WORKING_ GROUP_vaccine_hesitancy_final.pdf

SAGE Working Group on Vaccine Hesitancy (2013b) Vaccine hesitancy landscape analysis of organisations working on the issue of vaccine hesitancy. http://www.who.int/immunization/ sage/meetings/2013/april/1_Model_analyze_driversofvaccineCon fidence_22_March.pdf

Santos LB, Barreto CCM, Silva FLS, Silva KCDO (2011) Percepção das mães quanto à importância da imunização infantil. Perception of mothers regarding the importance of child immunization. Rev RENE 621-626

Schwarz NG, Gysels M, Pell C, Gabor J, Schlie M, Issifou S, Lell B, Kremsner PG, Grobusch MP, Pool R (2009) Reasons for nonadherence to vaccination at mother and child care clinics (MCCs) in Lambarene, Gabon. Vaccine 5371-5375. doi:10.1016/j.vaccine. 2009.0

Sheikh A, Iqbal B, Ehtamam A, Rahim M, Shaikh HA, Usmani HA, Nasir J, Ali S, Zaki M, Wahab TA, Wasim W, Aftab AA (2013) Reasons for non-vaccination in pediatric patients visiting tertiary care centers in a polio-prone country. Arch Public Health 19. doi:10.1186/0778-7367-71-19

Sheldon SJ, Alons C (2003) A study to describe barriers to childhood vaccination in Mozambique. Final report. [Maputo]. Ministerio da Saude, Mozambique

Sia D, Fournier P, Sondo BK (2011) Local vaccination cultures: the central role of health agents in rural settings of Burkina Faso Global Health Promotion. 18:68-80. doi:10.1177/175797591140 4747

Tadesse H, Deribew A, Woldie M (2009) Explorative assessment of factors affecting child immunization in Wonago district, Gedeo zone, South Ethiopia. Arch Med Sci 5(2):233-240

Tickner S, Leman PJ, Woodcock A (2006) Factors underlying suboptimal childhood immunisation. Vaccine 24:7030-7036. doi:10.1016/j.vaccine.2006.06.060

Tirado Otávaro AF, Moreno Uribe CM (2006) Factores asociados a las bajas coberturas de vacunación en Santa Bárbara (Antioquia). Med UPB 26(1):33-42
Topuzoglu A, Ay P, Hidiroglu S, Gurbuz Y (2007) The barriers against childhood immunizations: a qualitative research among socio-economically disadvantaged mothers. Eur J Public Health 348-352. doi:10.1093/eurpub/ck1250

Torun SD, Bakirci N (2006) Vaccination coverage and reasons for non-vaccination in a district of Istanbul. BMC Public Health $6: 125$

Torun SD, Demir F, Hidiroglu S, Kalaca S (2008) Measles vaccination coverage and reasons for non-vaccination. Public Health 192-194. doi:10.1016/j.puhe.2007.06.004

Trim K, Nagji N, Elit L, Roy K (2012) Parental knowledge, attitudes and behaviours towards human papillomavirus vaccination for their children: a systematic review from 2001 to 2011. Obstet Gynecol Int 2012:921236. doi:10.1155/2012/921236

Uddin MJ, Larson CP, Oliveras E, Khan AI, Quaiyum MA, Saha NC, Ahmed F, Khan IA, Shamsuzzaman (2008) Coverage of child immunization in rural hard-to-reach Haor areas of Bangladesh: acceptability of alternative strategies. International Centre for Diarrhoeal Disease Research, Bangladesh [ICDDR,B]

Wallace A, Dietz V, Cairns KL (2009) Integration of immunization services with other health interventions in the developing world: what works and why? Systematic literature review. Trop Med Int Health TMIH 14:11-19. doi:10.1111/j.1365-3156.2008.02196.x

WHO (2012a) Poliomyelitis: intensification of the global eradication initiative. WHO, Geneva

WHO (2012b) Global measles and rubella strategic plan 2012-2020. WHO, Geneva

WHO (2013) Strategic advisory group of experts (SAGE) on immunization. Terms of reference. WHO, Geneva

WHO (2014a) Principles and considerations for adding a vaccine to a national immunization programme: from decision to implementation and monitoring. World Health Organization, Geneva

WHO (2014b) Immunisation supply chain and logistics. A neglected bust essential system for national immunization programmes. WHO, Dept. Immunization, Vaccines and Biologicals, Geneva, Switzerland

WHO (2014c) Meeting of the strategic advisory group of experts on immunization, October 2014-conclusions and recommendations. WER 50 89:561-576

WHO (2014d) WHO/UNICEF coverage estimates 2013. http://apps. who.int/immunization_monitoring/globalsummary/timeseries/ tswucoveragebcg.html. Accessed Feb 2015

Williams S (2014) What are the factors that contribute to parental vaccine-hesitancy and what can we do about it? Hum Vaccines Immunother 10:2584-2595

World Bank (2014) Country and lending groups 2014. The World Bank. http://data.worldbank.org/about/country-classifications/ country-and-lending-groups. Accessed Feb 2014 